\title{
Nursing student perception and performance with collaborative testing
}

\author{
Sandra Rogers,; Theresa A. Gaffney, Eileen Caulfield \\ Malek School of Health Professions, Marymount University, United States
}

Received: October 7, 2020

DOI: $10.5430 /$ jnep.v11n5p54
Accepted: January 24, 2021

Online Published: January 25, 2021

\begin{abstract}
Background and objective: Collaboration is an important and necessary skill to function effectively within the practice of nursing and inter-professional teams. The purpose of this pilot study was to examine the impact of collaborative testing on nursing student content retention and student perception of the collaborative testing process.

Methods: A convenience sample of nursing students $(n=95)$ were grouped in random pairs and permitted to collaborate on exam 3 (of 5) in an entry level medical surgical nursing course. Students were surveyed with the 13-item survey, Student Evaluation of Collaborative Testing, after the collaborative exam.

Results and conclusions: There was a strong, positive correlation between students' exam 3 grades and the number of correct responses to exam 3 content items on the final exam, $r=.511, p<.001$. For every one-point increase on exam 3 grades, the number of correct responses on exam 3 content on the final exam increased by .511 . As such, students who scored higher on exam 3 also had more correct responses to exam 3 content on the final exam. There was a strong, positive correlation between students' exam 3 and final exam scores, $r=.536, p<.001$. It may (or may not) be the case that students' who perceived collaborative learning more positively were more impacted by the collaborative learning experience, resulting in higher scores on the final exam.
\end{abstract}

Key Words: Collaboration, Collaborative testing, Nursing student perception

\section{INTRODUCTION}

Collaboration is an important and necessary skill to function effectively within the practice of nursing and interprofessional teams. The Quality and Safety Education for Nurses (QSEN) competencies, or guidelines, are used throughout nursing education to guide preparation for basic practice as a skilled nurse. The QSEN guidelines consist of six competencies, one of which is teamwork and collaboration. This competency is believed to foster open communication, mutual respect, and shared decision making to achieve quality patient care. ${ }^{[1]}$

A primary goal of nursing education is to prepare students to work collaboratively with health care team members. Patient health care needs rely on health care professionals working collaboratively to enhance the coordination of care and to ensure better patient outcomes. ${ }^{[2]}$ Collaborative testing is defined as a collaborative learning strategy where students work together on a test and is one learning strategy that has provided the opportunity for students to learn and practice collaboration in a low-risk environment and without risk to patients. ${ }^{[2]}$

Several advantages have been theorized with collaborative testing in nursing education. Educators can provide environments that resemble real-world clinical practice, decision States.

*Correspondence: Sandra Rogers; Email: srogers@marymount.edu; Address: Malek School of Health Professions, Marymount University, United 
making situations where participants can pull from their knowledge and expertise and develop trust and confidence in their knowledge and in decision making. ${ }^{[3]}$ Collaborative testing gives learners the opportunity to develop skills not limited to collaboration alone. Improvement in communication, negotiation, and working in a team are a few that have been mentioned in prior literature. ${ }^{[3]}$ Active learning is involved and occurs when collaborative testing participants engage with other team members to determine the correct answer to a test question and when defending their decision.

Other benefits of collaborative testing that have been discussed among investigators includes a decrease in text anxiety along with enhanced learning. Students are able to use their critical thinking skills to analysis complex situations. This, as stated before, leads to promotion of teamwork with greater retention and transfer of knowledge. ${ }^{[4]}$ There has also been discussion that collaborative testing gives students the ability to go beyond their own knowledge and skills to achieve a deeper understanding of course materials while supporting their emotional and educational needs. However, scoring a collaborative test can take more time for educators and be somewhat more challenging than scoring a traditional test. It also requires students to come to a consensus on test answers and submit answers as a group. ${ }^{[5]}$

In summary, collaborative testing is a learning strategy that encourages students to participate, negotiate, and work together as a team during testing. ${ }^{[5]}$ Along with the many benefits of collaborative testing discussed, there is evidence that it also increases examination scores in nursing education. However, there is a lack of evidence related to collaborative testing and course content material retention. ${ }^{[6]}$

The purpose of this pilot study was to examine the impact of collaborative testing on nursing student perception of the collaborative testing method as well as content retention, an area that has been inadequately addressed in collaborative testing literature.

\section{Method}

This descriptive study utilized a convenience sample of nursing students enrolled in an entry level course in an accelerated nursing program. Participants were at least 18 years of age, able to read and write in English, and enrolled in the entry level nursing course during the fall. Following institutional review board approval, data was collected using an online self-report survey tool to measure student perception of collaborative testing. This was done through the use of the Student Evaluation of Collaborative Testing, a 13-item survey ${ }^{[7]}$ that was adapted from Cortwright et al., ${ }^{[7]}$ with 5-point Likert scales ( $1=$ completely disagree; $2=$ disagree;

Published by Sciedu Press
$3=$ neither agree nor disagree; $4=$ agree; $5=$ completely agree).

The collaborative testing method was similar to that described by Centrella-Nigro's study in 2012. ${ }^{[8]}$ Immediately following exam 3 in a traditional nursing in-class exam, where tests were given online and submitted individually, students were randomly assigned to pairs. Students were given a hard copy of the exam along with an answer sheet. They were allowed 15-minute to discuss the exam questions and had the option of changing a limited number of question answers. They did not have to change any answers if they preferred. At the end of 15 minutes, all hard copies of the exams and answer sheets were collected. Students' performance on exam 3 was compared at the end of the semester with their performance on the exam 3 subset within the comprehensive final exam for the course.

The outcome variable of content retention was measured by analyzing individual exam 3 content performance and comparing it to individual final exam performance on the exam 3 subset content, as well as overall mean performance on exam 3 and the final exam in the course. A paired $t$ test was used to compare the number of items students answered correctly on the original subset of questions to the number of items they answered correctly on the final subset of questions. Theorizing that retention will be demonstrated if a student correctly answers the same or more items on the final subset as on the original subset.

\section{Data analysis}

The objective of this study was to assess whether student collaboration improves retention of the material. Retention of material was operationalized as the number of correct responses on the final exam referring to exam 3 content ( $n$ $=25$ ). A correlational analysis was conducted to examine the relationship between exam 3 scores and the number of correct responses on exam 3 items on the final exam. The following null and alternative hypotheses were used to assess the research question:

H0: There is no relationship between students' scores on exam three and the number of correct responses on items on the final exam referring to exam three content.

H1: There is a relationship between students' scores on exam three and the number of correct responses on items on the final exam referring to exam three content.

Students' scores on exam 3 and number of correct responses on the final exam (for items referring to exam 3 content) were selected as the two variables of interest. Before any analyses were conducted, data were screened, coded, and imputed into the Statistical Package for the Social Sciences 
(SPSS) software.

First, descriptive statistics for each of the variables are reported, included measures of central tendency (mean, median) and variability (standard deviation, range). Then, the statistical assumptions of Pearson's $r$ correlation coefficient are assessed. If any of the assumptions are violated, the nonparametric Spearman's rank order correlation coefficient will be calculated. The alpha level (i.e. p-value) was set to .05 to determine statistical significance. After the correlational analysis, students' perceptions of the collaborative learning experience are generally assessed.

\section{Results}

Scores on Exam 3 and Final Exam (Exam 3 content) were available for 95 students. On Exam 3, scores ranged from 54 to 100 , with an average grade of $85.47(\mathrm{sd}=9.15)$. On the final exam (exam 3 content only), scores ranged from 11 to 25 correct responses, with an average of 20.95 (sd = 3.45) correct responses on items referring to exam 3 content. Additionally, Final Exam total grades were available for the sample. Final Exam grades ranged from 63 to 100, with an average grade of $87.86(\mathrm{sd}=8.37)$. A complete description of student exam results is found in Table 1 .

Table 1. Descriptive statistics of students' scores

\begin{tabular}{llll}
\hline Assessment & Mean (SD) & Median & Range \\
\hline Exam 3 & $85.47(9.15)$ & 86 & $54-100$ \\
Final Exam (Exam 3 content) & $20.95(3.45)$ & 22 & $11-25$ \\
Final Exam & $87.86(8.37)$ & 89 & $63-100$ \\
\hline
\end{tabular}

Correlational Analysis. In order to address this research question, the number of correct responses on exam 3 content on the final exam were calculated by summing the items on the final exam referring to exam 3 content $(n=25)$. Additionally, students' scores on exam 3 were reported. To analyze the relationship between the two variables, a correlational analysis was conducted. First, the three major assumptions of Pearson's $r$ correlation coefficient were assessed. These assumptions include, 1) the absence of bivariate outliers, 2) the assumption of linearity, and 3) the assumption of a bivariate normal distribution. Pearson correlational analysis examines the strength and direction of two variables based on their linear relationship with each other (Lane, 2013). Pearson's correlation coefficient $(r)$, ranges from -1 to 1 . An $r$ of -1 indicates perfect negative liner relationship between the variables, an $r$ of 0 indicates no linear relationship between the variables, and an $r$ of 1 indicates a perfect positive linear relationship between the variables.

First, a visual inspection of the data was completed using a scatterplot of the variables to search for bivariate outliers (see Figure 1). No bivariate outliers were identified. Additionally, through visual inspection of the scatterplots, the assumption of linearity for the relationship between exam 3 grades and final exam (exam 3 content items) was deemed to be tenable. Finally, it was also assumed that the data were bivariate normally distributed. Therefore, Pearson's $r$ correlation coefficient was determined to be the most appropriate statistical analysis to exam the research question.

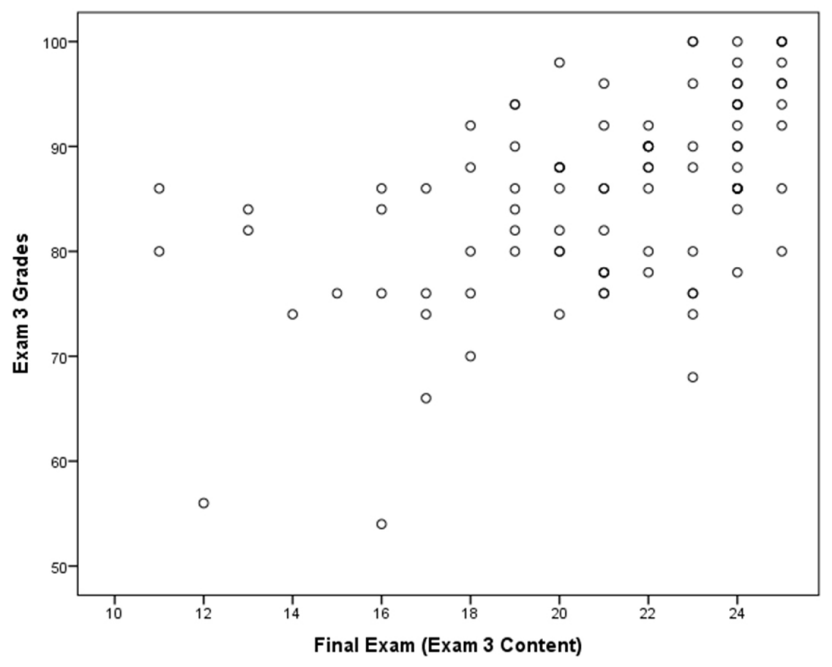

Figure 1. Scatterplot of Exam 3 Grades and Final Exam (Exam 3 Content)

A significant relationship was found between students' scores on exam 3 (a collaborative exam) and the final exam (exam 3 content). There was a strong, positive correlation between students' exam 3 grades and the number of correct responses to exam 3 content items on the final exam, $r=.511, p<.001$. For every one-point increase on exam 3 grades, the number of correct responses on exam 3 content on the final exam increased by .511. As such, students who scored higher on exam 3 also had more correct responses to exam 3 content on the final exam (see Figure 2).

Additionally, a significant relationship was found between students' scores on exam 3 and their final exam grades (overall). There was a strong, positive correlation between students' exam 3 and final exam scores, $r=.536, p<.001$. For every one-point increase on students' exam 3 scores, their final exam score increased by .536 points. Generally, students who did well on exam 3 also did well on the final exam. Students who did not do well on exam 3 did not tend to do well on the final exam (see Figure 3).

Based on these data, the null hypothesis is rejected. There is indeed a relationship between students' scores on exam 3 and the final exam (both overall, and exam 3 content). These results provide support for the research hypothesis 
that, collaborative learning (i.e. exam 3) improve retention of material.

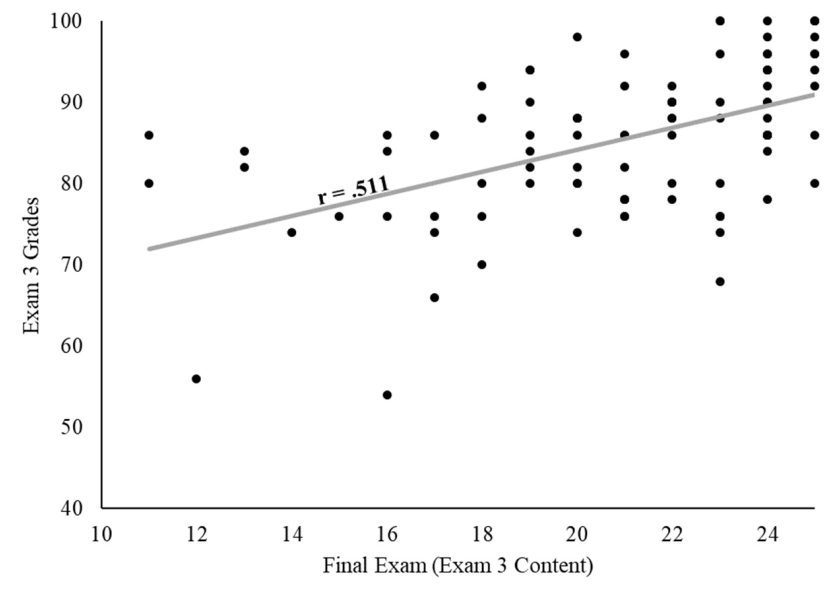

Figure 2. Relationship between Exam 3 and Final Exam (Exam 3 Content) scores

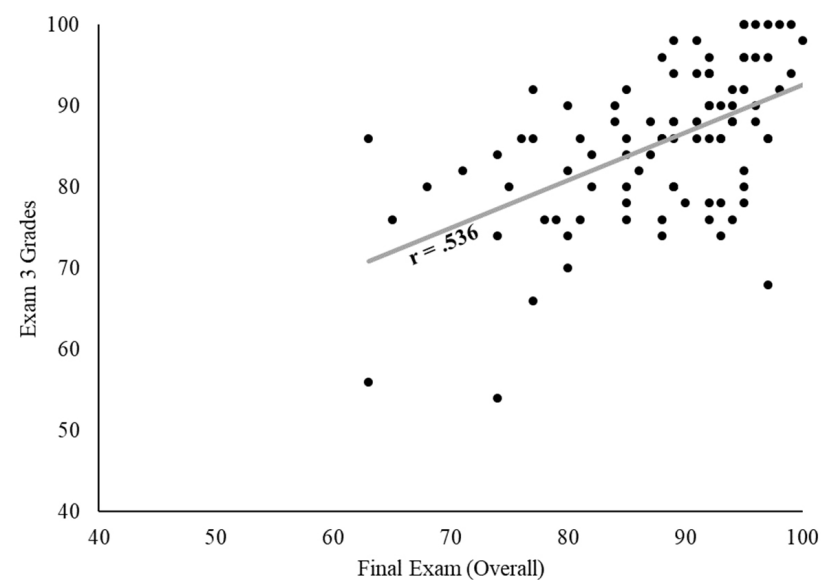

Figure 3. Relationship between Exam 3 and Final Exam (Overall) score

Student Perception of Collaborative Testing. The following evaluation questions were administered to students following completion of the course:

1) The purpose of and rationale behind the collaborative testing process was fully explained.

2) The collaborative testing process was not too lengthy or complex in its format.

3) The peer discussions on the group testing improved my level of confidence on the answers.

4) Every group member contributed to the learning process during the pyramid exam.

5) The level of peer (group) discussions was very high.

6) The immediate feedback given by the peer discussions was very positive.

7) The level of peer (group) discussions enhanced my understanding of the concepts.

8) My level of involvement during the collaborative exam discussions was high.

Published by Sciedu Press
9) I was able to later recall concepts because I had the opportunity to previously discuss them within the group.

10) This testing methodology provided the opportunity to discuss incorrect answers and fill in knowledge gaps.

11) This testing methodology was educationally attractive due to the novelty of this style and format.

12) This testing methodology was less stressful than traditional testing methods.

13) I would be interested in further classes with similar group testing methodologies.

Students responded on a 5-point Likert-type scale: $1=$ completely disagree; 2 = disagree; $3=$ neither agree nor disagree; $4=$ agree $; 5=$ completely agree. Aggregated across all items, most responses to the perception of collaborative testing were positive; $41.93 \%$ agree and $41.61 \%$ completely agree. There were a small percentage of negative perceptions of collaborative testing (1.38\% completely disagree, and $4.46 \%$ disagree). Specifically, Question 12, this testing method was less stressful than traditional testing, had the highest proportion of negative responses (18.9\%) of any of the items. However, in relative terms, negative responses to this item still represented less than a quarter of students. A breakdown of students' aggregated responses to each question are provided in Table 2 .

Results of this study support prior findings that student performance on examinations and exam scores are higher when completing the same examination in groups or pairs than when the students completed examinations individually. This improvement in exam performance for the group or pairs corroborates the notion that cooperative activities facilitate student learning. Study findings also support prior research in that collaborative testing improves student retention of course content as well as the value related to content retention. ${ }^{[7]}$ This finding emphasizes the pedagogical value of an examination and not just the simplistic view as the basis for grades only. Examinations can be used as a tool to not only evaluate performance but to enhance learning as well. Results from this study document that using exams as learning tools during collaborative testing increases student performance and retention.

\section{Summary AND CONClusion}

There was improved performance on exam 3 content that was included on the cumulative final exam. Further investigation of exam performance and the impact of collaborative testing is necessary. The findings could foster collaborative testing as a strategy in nursing courses throughout the nursing program to improve content retention; promote shared decision making among nursing students; and to ultimately achieve higher quality patient care. 
Table 2. Students' aggregated responses to each item evaluating perceptions of collaborative testing

\begin{tabular}{llllll}
\hline & Completely Disagree & Disagree & Neither Agree Nor Disagree & Agree & Completely Agree \\
\hline Question 1 & 0 & 6 & 6 & 37 & 46 \\
Question 2 & 4 & 2 & 4 & 38 & 46 \\
Question 3 & 2 & 8 & 21 & 32 & 32 \\
Question 4 & 0 & 1 & 7 & 45 & 42 \\
Question 5 & 1 & 2 & 3 & 45 & 44 \\
Question 6 & 0 & 3 & 16 & 41 & 35 \\
Question 7 & 3 & 4 & 10 & 51 & 27 \\
Question 8 & 0 & 0 & 2 & 37 & 56 \\
Question 9 & 1 & 3 & 11 & 44 & 35 \\
Question 10 & 1 & 1 & 4 & 43 & 46 \\
Question 11 & 0 & 4 & 17 & 35 & 39 \\
Question 12 & 4 & 14 & 20 & 32 & 25 \\
Question 13 & 1 & 7 & 10 & 37 & 40 \\
Total & 17 & 55 & 131 & 517 & 513 \\
Average & $1.38 \%$ & $4.46 \%$ & $10.62 \%$ & $41.93 \%$ & $41.61 \%$ \\
\hline
\end{tabular}

We also anticipated positive student perception of collaborative testing as based on the prior literature. Because individual data were not available for students' perceptions of collaborative testing, an overall perception score and reliability statistics could not be calculated. Therefore, the present study is unable to determine the impact of students' perceptions of collaborative learning on the retention of material learned collaboratively. In other words, it is beyond the scope of the present study to disentangle students' perceptions and test results. It may (or may not) be the case that students' who perceived collaborative learning more positively were more impacted by the collaborative learning experience, resulting in higher scores on the final exam. However, students' perceptions of the collaborative learning experience were generally positive. As with prior studies, ${ }^{[9,10]}$ the majority of students had positive responses (agree or completely agree) to all items and recommended this educational strategy be used for future examinations. Students also reported a decrease in their anxiety during the exam, which could play a role in a reported positive testing experience.

Witnessing the collaborative exam process reinforced what other researchers in this area of study had observed. ${ }^{[11]}$ During the collaborative portion of the examination, faculty had the opportunity to listen to student discussions as students reviewed the exam and individual questions. Students were heard defending their answers; providing rationale; and were able to work together to eliminate distractors. Students shared their interpretation of the questions and selections to better understand what was being asked. This team effort ruled out each distractor and served in selecting what they believed as a team to be the correct answer. Through this process, students were also observed questioning their own knowledge base by trusting their testing partner's understanding and discovering why their answers may not be accurate. By observing how their collaborative testing partner analyzed questions, students improved their own critical thinking skills and test taking skills. This is especially true for complex, multiple-choice style questions that require more than basic knowledge, requiring the ability to apply, analyze, synthesize and/or evaluate data. It also allowed them the opportunity to improve their examination score.

To function as a collaborative member of an interdisciplinary health care team is a critical skill required in the practice of nursing. Testing proficiency is important too as it is vital in obtaining licensure. Collaborative testing proceeds beyond the benefits of answering questions correctly. Skills that students perceive as positive following the collaborative testing experience are beneficial as well. These skills include team building, negotiation, and communication skills that develop their ability to supply rationale for decision making. The use of collaborative testing as an active learning strategy and not just an assessment of knowledge, provides multiple opportunities for students to cultivate skills that will benefit them as they enter professional nursing practice. ${ }^{[12]}$

Other studies have also shown that students found collaborative testing to be a non-threatening approach to learning and that exchanges with their fellow student(s) facilitated both their understanding of concepts and strengthened their confidence in their ability to answer questions correctly. However, while students perceived collaborative testing to be both 
more helpful and less stressful than traditional testing, the absence of improved content retention in prior studies suggests that collaborative testing may not be a robust method for improving student learning. These studies looked at a variety of student populations and across different disciplines in regard to collaborative testing and content retention. ${ }^{[6]}$ With only a couple studies having demonstrated improved content retention with collaborative testing ${ }^{[7,13]}$ educators need to be mindful that although the benefits of teamwork, communication, and collaboration have been determined, more research in the area of content retention needs to be done. Our current study results add to the growing body of evidence that collaborative testing does assist with content retention. Therefore, collaborative testing or any intervention that might help students retain information is beneficial and should be considered. Again, additional research to confirm these results related to content retention and to explore what period of time information is retained following collaborative testing is needed. In regard to student perception of collaborative testing, future research might need to consider examining each items' impact individually on the overall collaborative learning experience.

Collaborative testing should be viewed as one more instrument that nursing educators possess to not only assess competency but to employ in the building of communication and negotiation skills. Both the benefits and constraints of collaborative testing must be examined by nurse educators before integrating the teaching strategy into their course(s). This pilot study offers guidance to larger scale studies in examining the benefits of collaborative testing in nursing programs.

\section{CONFLICTS OF INTEREST Disclosure}

The authors declare that there is no conflict of interest.

\section{REFERENCES}

[1] QSEN Institute. Published November 30, 2019. Accessed December 1, 2019. Available from: https://qsen.org/competencies/gr aduate-ksas/\#teamwork_collaboration

[2] Sandahl SS. Collaborative testing as a learning strategy in nursing education: a review of the literature. Nurs Educ Perspect. 2009; 30(3): 171-175.

[3] Billings DM. Collaborative Testing. J Contin Educ Nurs. 2017; 48(7): 302-303. PMid:28658497 https : //doi .org/10.3928/00 220124-20170616-06

[4] Wiggs CM. Collaborative testing: assessing teamwork and critical thinking behaviors in baccalaureate nursing students. Nurse Educ Today. 2011; 31(3): 279-282. PMid:21084136 https ://doi.org/ $10.1016 / j \cdot$ nedt .2010 .10 .027

[5] Crawford D. Team testing teaches collaboration: Nursing. 2018; 48(4): 18-20. PMid:29561365 https : //doi .org/10.1097/01.N URSE. $0000531023.75781 . \mathrm{d} 8$

[6] Leight H, Saunders C, Calkins R, et al. Collaborative Testing Improves Performance but Not Content Retention in a Large-Enrollment Introductory Biology Class. Ebert-May D, ed. LSE. 2012; 11(4): 392-401. PMid:23222835 https://doi.org/10.1187/cbe. 12 -04-0048

[7] Cortright RN, Collins HL, Rodenbaugh DW, et al. Student retention of course content is improved by collaborative-group test- ing. Adv Physiol Educ. 2003; 27(1-4): 102-108. PMid:12928319 https://doi.org/10.1152/advan.00041.2002

[8] Centrella-Nigro AM. Collaborative testing as posttest review. Nurs Educ Perspect. 2012; 33(5): 340-341. PMid:23061194 https: //doi.org/10.5480/1536-5026-33.5.340

[9] Rivaz M, Momennasab M, Shokrollahi P. Effect of collaborative testing on learning and retention of course content in nursing students. J Adv Med Educ Prof. 2015; 3(4): 178-182.

[10] Hickey BL. Lessons learned from collaborative testing. Nurse Educ. 2006; 31(2): 88-91. PMid:16601617 https://doi.org/10.109 7/00006223-200603000-00012

[11] Duane BT, Satre ME. Utilizing constructivism learning theory in collaborative testing as a creative strategy to promote essential nursing skills. Nurse Education Today. 2014; 34(1): 31-34. PMid:23608232 https://doi.org/10.1016/j.nedt.2013.03.005

[12] Hanna K, Roberts T, Hurley S. Collaborative Testing as NCLEX Enrichment. Nurse Educ. 2016; 41(4): 171-174. PMid:26771942 https://doi.org/10.1097/NNE.0000000000000241

[13] Green R, Worthey T, Kerven J. Collaborative Testing: An Effective Invitational Strategy for High-Stakes Testing in Nursing. J Nurs Educ. 2018; 57(5): 291-295. PMid:29718519 https://doi.org/10.3 928/01484834-20180420-07 